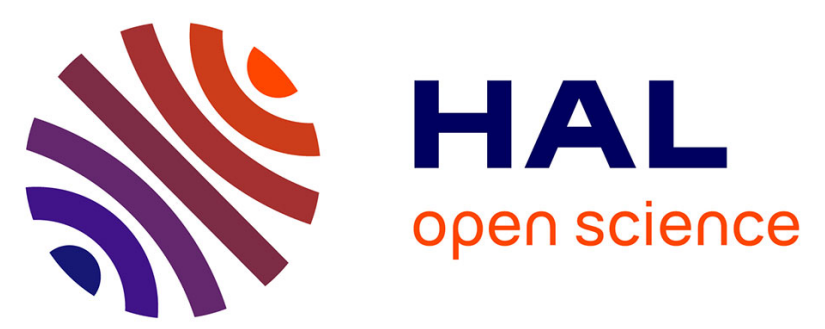

\title{
Application of Fundamental In-Body Radiation Limitations to Practical Design of Antennas for Implantable Bioelectronics
}

D. Nikolayev, W. Joseph, M. Zhadobov, L. Martens, R. Sauleau, A.K. Skrivervik

\section{To cite this version:}

D. Nikolayev, W. Joseph, M. Zhadobov, L. Martens, R. Sauleau, et al.. Application of Fundamental In-Body Radiation Limitations to Practical Design of Antennas for Implantable Bioelectronics. 2020 IEEE MTT-S International Microwave Biomedical Conference, IMBioC 2020, Dec 2020, Toulouse, France. pp.9384901, 10.1109/IMBIoC47321.2020.9384901 . hal-03248668

\section{HAL Id: hal-03248668 https://hal.science/hal-03248668}

Submitted on 20 Oct 2021

HAL is a multi-disciplinary open access archive for the deposit and dissemination of scientific research documents, whether they are published or not. The documents may come from teaching and research institutions in France or abroad, or from public or private research centers.
L'archive ouverte pluridisciplinaire HAL, est destinée au dépôt et à la diffusion de documents scientifiques de niveau recherche, publiés ou non, émanant des établissements d'enseignement et de recherche français ou étrangers, des laboratoires publics ou privés. 


\section{Application of Fundamental In-Body Radiation Limitations to Practical Design of Antennas for Implantable Bioelectronics}

\author{
Denys Nikolayev \\ IETR - UMR 6164 \\ Univ Rennes, CNRS \\ Rennes, France \\ d@deniq.com
}

\author{
Wout Joseph \\ INTEC - WAVES \\ imec / Ghent University \\ Ghent, Belgium \\ Wout.Joseph@ugent.be
}

Ronan Sauleau

IETR - UMR 6164

Univ Rennes, CNRS

Rennes, France

Ronan.Sauleau@univ-rennes1.fr

\author{
Maxim Zhadobov \\ IETR - UMR 6164 \\ Univ Rennes, CNRS \\ Rennes, France \\ Maxim.Zhadobov@univ-rennes1.fr
}

\author{
Luc Martens \\ INTEC - WAVES \\ imec / Ghent University \\ Ghent, Belgium \\ Luc1.Martens@ugent.be
}

Anja K. Skrivervik
$M A G-S C I-S T I-A S$
EPFL

Lausanne, Switzerland

Anja.Skrivervik@epfl.ch

\begin{abstract}
Fundamental in-body limitations on achievable radiation efficiency could provide decision-making assistance to engineers working on antennas for implantable bioelectronics. In this study, proof-of-concept conformal microstrip antennas are proposed based on these theoretical foundations. In particular, maximizing the effective aperture and loading the antenna with materials having the permittivity higher than that of surrounding tissues is a promising solution for increasing the radiation efficiency. The operating frequencies are tuned to operate within the optimal range for deep-body implantation: 434,868 , and 1400 MHz. The achieved radiation efficiencies at these frequencies are $0.4 \%, 2.2 \%$, and $1.2 \%$, respectively, when simulated in a $\varnothing 100$ mm spherical phantom with muscle-equivalent electromagnetic properties. The radiation performance at each frequency is compared to the fundamental limitations and closely approach them. Prototypes are characterized for the experimental validation.
\end{abstract}

Index Terms-biomedical applications, conformal antenna, implantable, in-body, ingestible, microstrip antennas.

\section{INTRODUCTION}

Implantable bioelectronics is an emerging technology having many promising applications in medicine, clinical research, and basic science [1]. Establishing robust communication between in-body bioelectronics and external equipment is challenging because of extremely low radiation efficiencies $\eta<0.1 \%$. The main reasons are power dissipation in tissues (due to attenuation and strong tissue-air wave-impedance contrast) as well as the miniature size of the radiating elements [2]. Efficient in-body antennas would also help minimizing errors in path loss characterization in vivo [3], [4].

A range of antennas with different configurations and operating frequencies has been already proposed for bioelectronic capsule applications [5]-[10]. Robustness to heterogeneous and uncertain electromagnetic (EM) properties of surrounding tissues was considered in [11]-[14] and a reconfigurable cap-

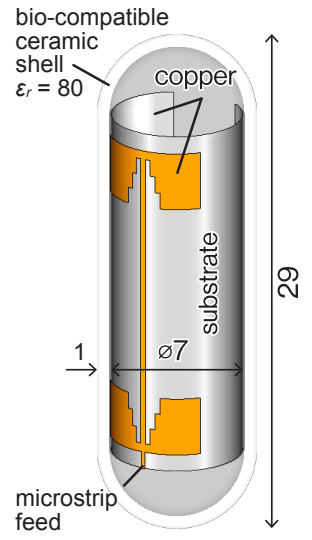

(a)

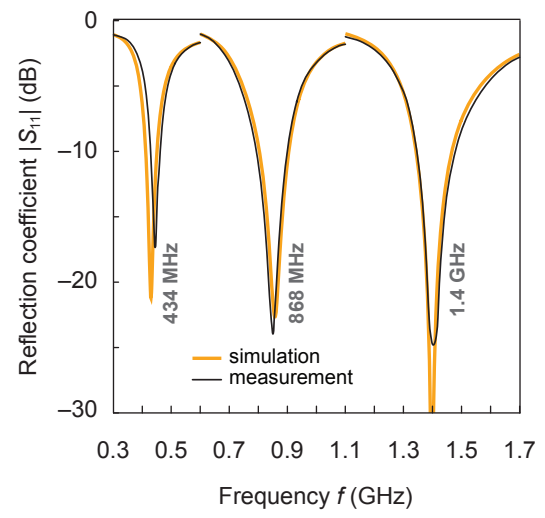

(b)
Fig. 1. (a) Miniaturized conformal-patch antenna design and dimensions of the capsule (units: millimeters). An example optimized for the $868-\mathrm{MHz}$ band is shown here; detailed antenna dimensions individually optimized for all operating frequencies are given in [21]. (b) Simulated and measured reflection coefficients $\left|S_{11}\right|$.

sule antenna with no nulls in radiation pattern was proposed in [15]. Impact of dielectric loading on radiation efficiency was studied in [16]-[18]. Dielectric loading by materials such as alumina or zirconia have been studied for in-body antenna applications in [19], [20]. Effects of loading by higher permittivity materials were considered in [21]. Such materials have a potential of maximizing the tissue-loading effect while reducing losses in the near-field [22], [23].

In this study, we apply the fundamental in-body limitations [18], [23] to study the design of a superstrate-loaded $\left(\varepsilon_{r} \approx\right.$ 80) capsule-conformal antenna. The design is tuned to three different operating frequencies spanning the optimal frequency 
range for in-body applications: 434, 868, and $1400 \mathrm{MHz}$ [24]. The radiation efficiencies at these frequencies are compared to the fundamental limitations and closely approach them. This proof-of-concept antenna design remains simple and conforms to the inner wall of a 1-mm-thick ceramic shell. The theoretical effect of shell thickness on the efficiency is studied as well.

\section{Miniaturized Conformal-Patch Design}

The antenna designs conform to the inner surface of the $29 \times$ $\varnothing 9 \mathrm{~mm}$ capsule (Fig. 1a). The shell is made of biocompatible low-loss ceramic with $\varepsilon_{r} \approx 80$ close to the maximum value encountered in a human body [25]. The proposed antennas are of a cylinder-conformal microstrip type and are designed to operate similarly to a half-wave patch [21]. The radiating edges are spaced out between two extremities of the cylinder, and such a configuration allows for the improved aperture efficiency that leads to higher achievable efficiency [18].

The miniaturization is achieved in part using dielectric loading by surrounding tissues and the ceramic superstrate. An Hantenna technique was used to further miniaturize the antenna [26]. The final design consists of two radiating elements linked by a high-impedance microstrip (Fig. 1a). For the $434-\mathrm{MHz}$ design, the high-impedance microstrip had to be meandered to increase its physical length.

\section{NumericAl RESULts}

CST Microwave Studio 2018 was used to analyze and optimize the antennas [27]. Detailed description of the numerical approach is given in [28]. Fig. 1b shows the impedance characteristics of the proposed antennas in muscle-equivalent environment. As for the radiation performance, the maximum simulated gains $G$ are $-28,-16$, and $-16 \mathrm{dBi}$, and the radiation efficiencies $\eta$ are $0.4 \%, 2.2 \%$, and $1.2 \%$ for the $434 \mathrm{MHz}$, $868 \mathrm{Mhz}$, and 1.4-GHz designs, respectively. Fig. 2a shows the full patterns.

Fig. $2 \mathrm{~b}$ gauges the proposed designs against the maximum achievable efficiencies of corresponding theoretical $\mathrm{TM}_{10}$ and $\mathrm{TE}_{10}$ sources in a $\varnothing 100-\mathrm{mm}$ spherical muscle-equivalent phantom [18]. The theoretical sources have been calculated with the following parameters corresponding to the proposed designs: $L=18 \mathrm{~mm}, R=3.5 \mathrm{~mm}$, and $T=1 \mathrm{~mm}$. Owing to heavy dielectric loading, the 434-MHz design exceeds $\eta$ of the $\mathrm{TM}_{10}$ source. However, at this frequency, higher $\eta$ can be achieved using a magnetic $\mathrm{TE}_{10}$ source. The $868 \mathrm{MHz}$ antenna is the most efficient among the three designs: it surpasses $\max (\eta)$ of $\mathrm{TE}_{10}$ and closely approaches $\mathrm{TM}_{10}$. The radiation efficiency of the 1.4-GHz design is below $\max (\eta)$ of both $\mathrm{TM}_{10}$ and $\mathrm{TE}_{10}$. Its increased directivity $D=4 \mathrm{dBi}$ results in elevated power dissipation in the near field of the antenna [23].

Fig. 3 shows the theoretical effect of a lossless (i.e. $\sigma=0 \mathrm{~S} \cdot \mathrm{m}^{-1}$ ) shell thickness $T$ the maximum achievable efficiency $\eta\left(f_{\text {opt }}\right)$. The radiation efficiency is linearly proportional to $T$ for both source formulations although the effect is stronger for $\mathrm{TM}_{10}$ due to the reduction of losses in the predominantly electric near field of this source type.
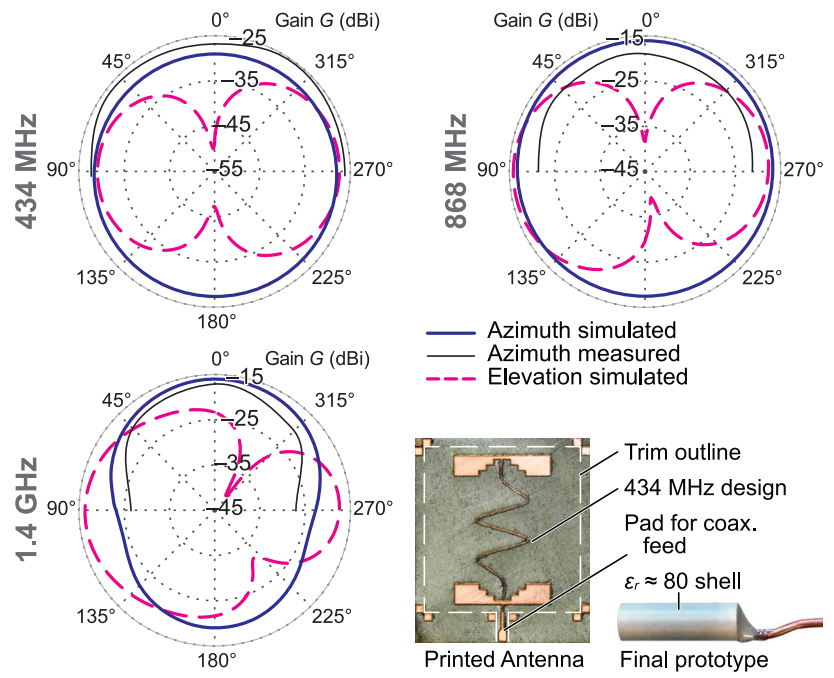

(a)

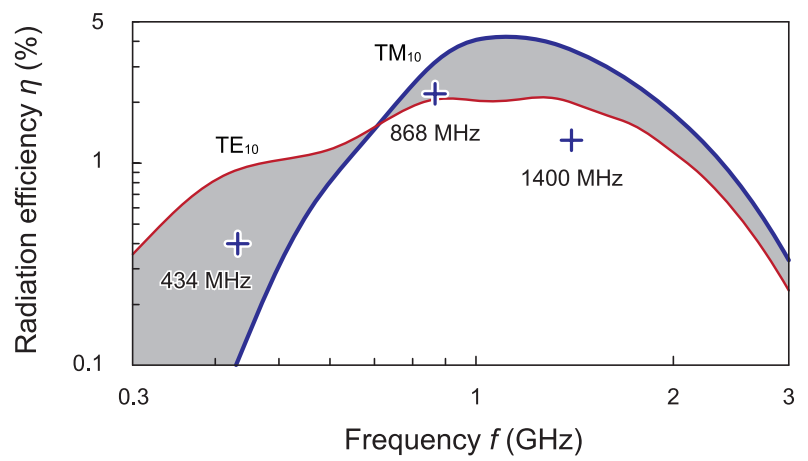

(b)

Fig. 2. Radiation performance of the proof-of-concept conformal-patch antenna individually optimized for three different operating frequencies. The inset shows the antenna prototype. (a) Simulated and measured radiation patterns in the $100-\mathrm{mm}$ spherical phantom with muscleequivalent properties.(b) Radiation efficiency comparison of the proposed designs with the maximal achievable efficiencies of theoretical $\mathrm{TM}_{10}$ and $\mathrm{TE}_{10}$ sources. The efficiency of theoretical sources was calculated using the methodology given in [18].

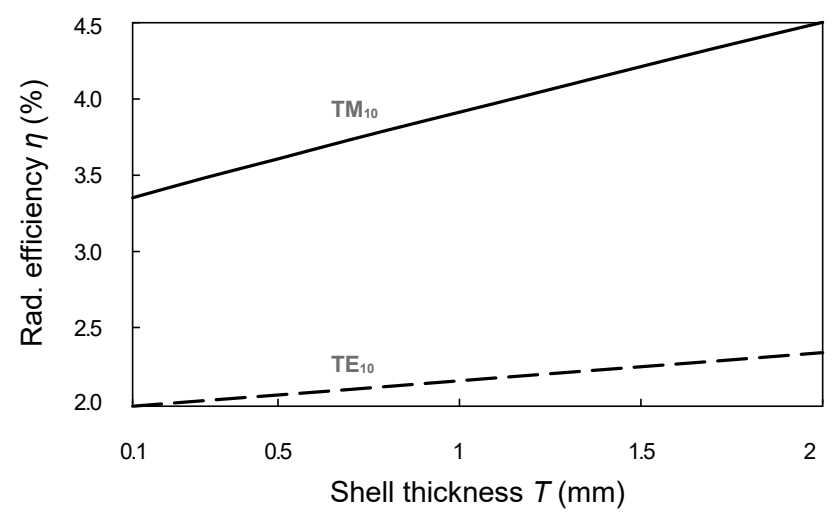

Fig. 3. Maximum achievable efficiency $\eta\left(f_{\text {opt }}\right)$ as a function of capsule shell thickness. The source dimensions are $L=18 \mathrm{~mm}, R_{C}=3.5 \mathrm{~mm}$. 


\section{EXPERIMENTAL VALIDATION}

The proposed antennas were manufactured on the 101.6$\mu \mathrm{m}$-thick Rogers $3850 \mathrm{HT}$ substrate and then inserted into a $28 \times \varnothing 9 \mathrm{~mm}$ ceramic shell TCI Ceramics "K-80," $\varepsilon_{r}=80$ [29]. Detailed prototyping procedure is given in [21]. To mimic the tissue properties, we prepared corresponding liquid muscleequivalent phantoms for each $f_{d}$. We used a water-sugar-salt formula [30] to achieve target EM properties. EM properties were validated using SPEAG DAK-12 probe.

Fig. 1b shows good agreement in terms of $\left|S_{11}\right|$. The resonance frequency deviation of about $7 \%$ for the $434-\mathrm{MHz}$ design could be due to relatively low precision manufacturing methodology (laser ablation). Radiation performance was measured in a fully anechoic chamber as detailed in [21]. The radiation was measured in the azimuth plane for $\theta \in\left[90^{\circ}, 270^{\circ}\right]$ due to the positioner angle limitations (see [19]). Fig. 2a shows the far-field characterization results. The radiation patterns and maximum gain values are consistent with the simulated ones.

\section{CONCLUSION}

We studied the proof-of-concept design of in-body dielectric-loaded conformal-patch antennas. The results are consistent with the theoretical findings on fundamental in-body radiation limitations. In addition, the results demonstrate in practice that electric antennas could achieve higher efficiencies than the magnetic ones provided they operate close to an optimal frequency for a given implantation depth [24]. Note that the magnetic antennas show better theoretically achievable efficiency when operating well below the optimal frequency range (Fig. 2b, $\mathrm{TE}_{10}$ ). Future work on this subject includes exploring higher permittivity materials as well as implementing the developed approach into multi-band in-body antennas.

\section{ACKNOWLEDGMENT}

The authors would like to thank J.-C. Le Cun (IETR) for his help with the antenna substrate manufacturing using laser ablation, M. Van den Bossche and L. Verloock (UGent) for helping with the final assembly of the capsule prototypes.

\section{REFERENCES}

[1] A. Kiourti and K. S. Nikita, "A review of in-body biotelemetry devices: implantables, ingestibles, and injectables," IEEE Trans. Biomed. Eng., vol. 64, no. 7, pp. 1422-1430, Jul. 2017.

[2] D. Nikolayev, M. Zhadobov, P. Karban, and R. Sauleau, "Conformal antennas for miniature in-body devices: The quest to improve radiation performance," URSI Rad. Sci. Bull., vol. 363, pp. 52-64, Dec. 2017.

[3] S. Benaissa et al., "Experimental characterization of in-to-out-body path loss at $433 \mathrm{MHz}$ in dairy cows," Electron. Lett., vol. 55, no. 7, pp. 422 424, Apr. 2019.

[4] S. Perez-Simbor, C. Andreu, C. Garcia-Pardo, M. Frasson, and N. Cardona, "UWB path loss models for ingestible devices," IEEE Trans. Antennas Propag., vol. 67, no. 8, pp. 5025-5034, Aug. 2019.

[5] Z. Jiang et al., "Wideband loop antenna with split ring resonators for wireless medical telemetry," IEEE Antenn. Wireless Propag. Lett., vol. 18, no. 7, pp. 1415-1419, Jul. 2019.

[6] W. Lei and Y. Guo, "Design of a dual-polarized wideband conformal loop antenna for capsule endoscopy systems," IEEE Trans. Antennas Propag., vol. 66, no. 11, pp. 5706-5715, Nov. 2018.

[7] M. S. Miah et al., "Antenna system design for improved wireless capsule endoscope links at $433 \mathrm{MHz}$, , IEEE Trans. Antennas Propag., vol. 67, no. 4, pp. 2687-2699, Apr. 2019.
[8] Y. Peng , K. Saito, and K. Ito, "Antenna design for impulse-radiobased wireless capsule endoscope communication systems," IEEE Trans. Antennas Propag., vol. 66, no. 10, pp. 5031-5042, Oct. 2018.

[9] J. Wang et al., "An implantable and conformal antenna for wireless capsule endoscopy," IEEE Antenn. Wireless Propag. Lett., vol. 17, no. 7, pp. 1153-1157, Jul. 2018.

[10] Z. Duan, L. J. Xu, S. Gao, and W. Geyi, "Integrated design of wideband omnidirectional antenna and electronic components for wireless capsule endoscopy systems," IEEE Access, vol. 6, pp. 29626-29636, May 2018.

[11] Y. Feng, Y. Li, L. Li, B. Ma, H. Hao, and L. Li, "Tissue-dependent co-matching method for dual-mode antenna in implantable neurostimulators," IEEE Trans. Antennas Propag., vol. 67, no. 8, pp. 5253-5264, Aug. 2019.

[12] Z. Bao, Y. X. Guo, and R. Mittra, "An ultrawideband conformal capsule antenna with stable impedance matching," IEEE Trans. Antennas Propag., vol. 65, no. 10, pp. 5086-5094, Oct. 2017.

[13] D. Nikolayev, M. Zhadobov, and R. Sauleau, "Immune-to-detuning wireless in-body platform for versatile biotelemetry applications," IEEE Trans. Biomed. Circuits Syst., vol. 13, no. 2, Jan. 2019.

[14] M. K. Magill, G. A. Conway, and W. G. Scanlon, "Tissue-independent implantable antenna for in-body communications at $2.36-2.5 \mathrm{GHz}$,' IEEE Trans. Antennas Propag., vol. 65, no. 9, pp. 4406-4417, Sep. 2017.

[15] Z. Bao, Y.-X. Guo, and R. Mittra, "Conformal capsule antenna with reconfigurable radiation pattern for robust communications," IEEE Trans. Antennas Propag., vol. 66, no. 7, pp. 3354-3365, Apr. 2018.

[16] D. Nikolayev, M. Zhadobov, and R. Sauleau, "Impact of tissue electromagnetic properties on radiation performance of in-body antennas," IEEE Antenn. Wireless Propag. Lett., vol. 17, no. 8, pp. 1440-1444, Aug. 2018.

[17] T. Dissanayake, K. P. Esselle, and M. R. Yuce, "Dielectric loaded impedance matching for wideband implanted antennas," IEEE Trans. Microw. Theory Techn., vol. 57, no. 10, pp. 2480-2487, Oct. 2009.

[18] D. Nikolayev, W. Joseph, M. Zhadobov, R. Sauleau, and L. Martens, "Optimal radiation of body-implanted capsules," Phys. Rev. Lett., vol. 122, no. 10, p. 108101, Mar. 2019.

[19] D. Nikolayev, M. Zhadobov, L. Le Coq, P. Karban, and R. Sauleau, "Robust ultra-miniature capsule antenna for ingestible and implantable applications," IEEE Trans. Antennas Propag., vol. 65, no. 11, pp. 61076119, Nov. 2017

[20] F. Merli et al., "Design, realization and measurements of a miniature antenna for implantable wireless communication systems," IEEE Trans. Antennas Propag., vol. 59, no. 10, pp. 3544-3555, Oct. 2011.

[21] D. Nikolayev, W. Joseph, A. K. Skrivervik, M. Zhadobov, L. Martens, and R. Sauleau, "Dielectric-loaded conformal microstrip antennas for versatile in-body applications," IEEE Antenn. Wireless Propag. Lett., vol. 18, no. 12, pp. 2686-2690, Dec. 2019.

[22] F. Merli, B. Fuchs, J. R. Mosig, and A. K. Skrivervik, "The effect of insulating layers on the performance of implanted antennas," IEEE Trans. Antennas Propag., vol. 59, no. 1, pp. 21-31, Jan. 2011.

[23] A. K. Skrivervik, M. Bosiljevac, and Z. Sipus, "Fundamental limits for implanted antennas: Maximum power density reaching free space," IEEE Trans. Antennas Propag., vol. 67, no. 8, pp. 4978-4988, Aug. 2019.

[24] D. Nikolayev, M. Zhadobov, P. Karban, and R. Sauleau, "Electromagnetic radiation efficiency of body-implanted devices," Phys. Rev. Applied, vol. 9, no. 2, p. 024033, Feb. 2018.

[25] S. Gabriel, R. W. Lau, and C. Gabriel, "The dielectric properties of biological tissues: II. Measurements in the frequency range $10 \mathrm{~Hz}$ to 20 GHz,’ Phys. Med. Biol., vol. 41, pp. 2251-2269, Nov. 1996.

[26] J. Anguera, L. Boada, C. Puente, C. Borja, and J. Soler, "Stacked Hshaped microstrip patch antenna," IEEE Trans. Antennas Propag., vol. 52, no. 4, pp. 983-993, Apr. 2004.

[27] Computer Simulation Technology AG, CST Microwave Studio, Feb. 20, 2018. [Online]. Available: http://www.cst.com

[28] D. Nikolayev, Z. Kubík, P. Karban, and J. Skála, "Impedance analysis of transmission line cells for EMC applications using Agros2D," Appl. Math. Comput., vol. 289, pp. 381-387, Oct. 2016.

[29] TCI Ceramics, $K-80$, Feb. 20, 2018. [Online]. Available: http:// www.magneticsgroup.com/m_dielec.htm

[30] C. G. Malmberg and A. A. Maryott, "Dielectric constants of aqueous solutions of dextrose and sucrose," J. Res. Natl. Bur. Stand., vol. 45, no. 4, pp. 299-303, 1950. 